\title{
Organizational Influences on Interdisciplinary Interactions during Research and Design of Large-Scale Complex Engineered Systems
}

\author{
Anna-Maria Rivas McGowan ${ }^{1}$ \\ NASA Langley Research Center, Hampton, VA, 23681 \\ Colleen M. Seifert ${ }^{2}$ and Panos Y. Papalambros ${ }^{3}$ \\ University of Michigan, Ann Arbor, MI 48109
}

\begin{abstract}
The design of large-scale complex engineered systems (LaCES) such as aircraft is inherently interdisciplinary where multiple engineering disciplines, drawing from a team of hundreds to thousands of engineers and scientists, are woven together throughout the research, development, and systems engineering processes to realize one system. Though research and development (R\&D) is typically focused in single disciplines, the interdependencies involved in LaCES require interdisciplinary $R \& D$ efforts. This study investigates the interdisciplinary interactions that take place during the $R \& D$ and early conceptual design phases in the design of LaCES. Our theoretical framework is informed by both engineering practices and social science research on complex organizations. This paper provides a preliminary perspective on some of the organizational influences on interdisciplinary interactions based on organization theory (specifically sensemaking), data from a survey of LaCES experts, and the authors' experience in research and design. The analysis reveals couplings between the engineered system and the organization that creates it. Survey respondents noted the importance of interdisciplinary interactions and their significant benefit to the engineered system, such as innovation and problem mitigation. Substantial obstacles to interdisciplinarity are uncovered beyond engineering that include communication and organizational challenges. Addressing these challenges may ultimately foster greater efficiencies in the design and development of LaCES and improved system performance by assisting with the collective integration of interdependent knowledge bases early in the R\&D effort. This research suggests that organizational and human dynamics heavily influence and even constrain the engineering effort for large-scale complex systems.
\end{abstract}

\section{Introduction}

Large-Scale Complex Engineered Systems (LaCES) represent a unique genre of engineered systems that are core to the fabric of most industrialized nations for infrastructure and defense needs. LaCES (shown in Figure 2) include aerospace (e.g., aircraft, space systems), large maritime (e.g., submarines, aircraft carriers), nuclear (e.g., power plants), and major civil infrastructure systems (e.g., water supply systems, electric power grids, offshore oilrigs, and air and ground transportation systems). These engineered systems are unique in their blend of extremes in size, risk, and organizations. High technical and financial risk levels are common, with systems costing in the tens of millions to billions of dollars. The nature of LaCES makes it often too difficult, risky, expensive, or impossible to use conventional trial-and-error engineering methods and, often, the final "prototype" is the first and only complete system trial.

The organizations involved in LaCES development are similarly extensive. They typically include one or more government agencies, as well as a diverse array of universities and small and large contractors, each with their own sub-contractors. For example, the development of the Next Generation Air Transportation System in the U.S. is

\footnotetext{
${ }_{1}^{1}$ Senior Aerospace Engineer, Aeronautics Research Directorate, M/S 254, AIAA Associate Fellow.

${ }^{2}$ Professor, Department of Psychology, 3042 East Hall, Ann Arbor, MI 48109.

${ }^{3}$ Professor, Mechanical Engineering and Integrative Systems and Design, 2250 GGBrown, Ann Arbor, MI 48104, AIAA Member.
}

Reference Info: McGowan, A. R.; Seiftert, C. M., and Papalambros, P. Y., "Organizational Influences on Interdisciplinary Interactions During Research and Design of Large-Scale Complex Engineered Systems," 14th AIAA/ISSMO MA\&O Conference, Indianapolis, IN; September, 2012; Paper Number: 2012-5574. 
underway with the joint influence of eight federal agencies and a considerable number of local municipalities and businesses. ${ }^{1}$ It is not uncommon for the combined design and development organization that develops one system to total hundreds or thousands of engineers and scientists. This system "team" is usually also geographically dispersed, with many team members never personally interacting with large portions of the LaCES organization.

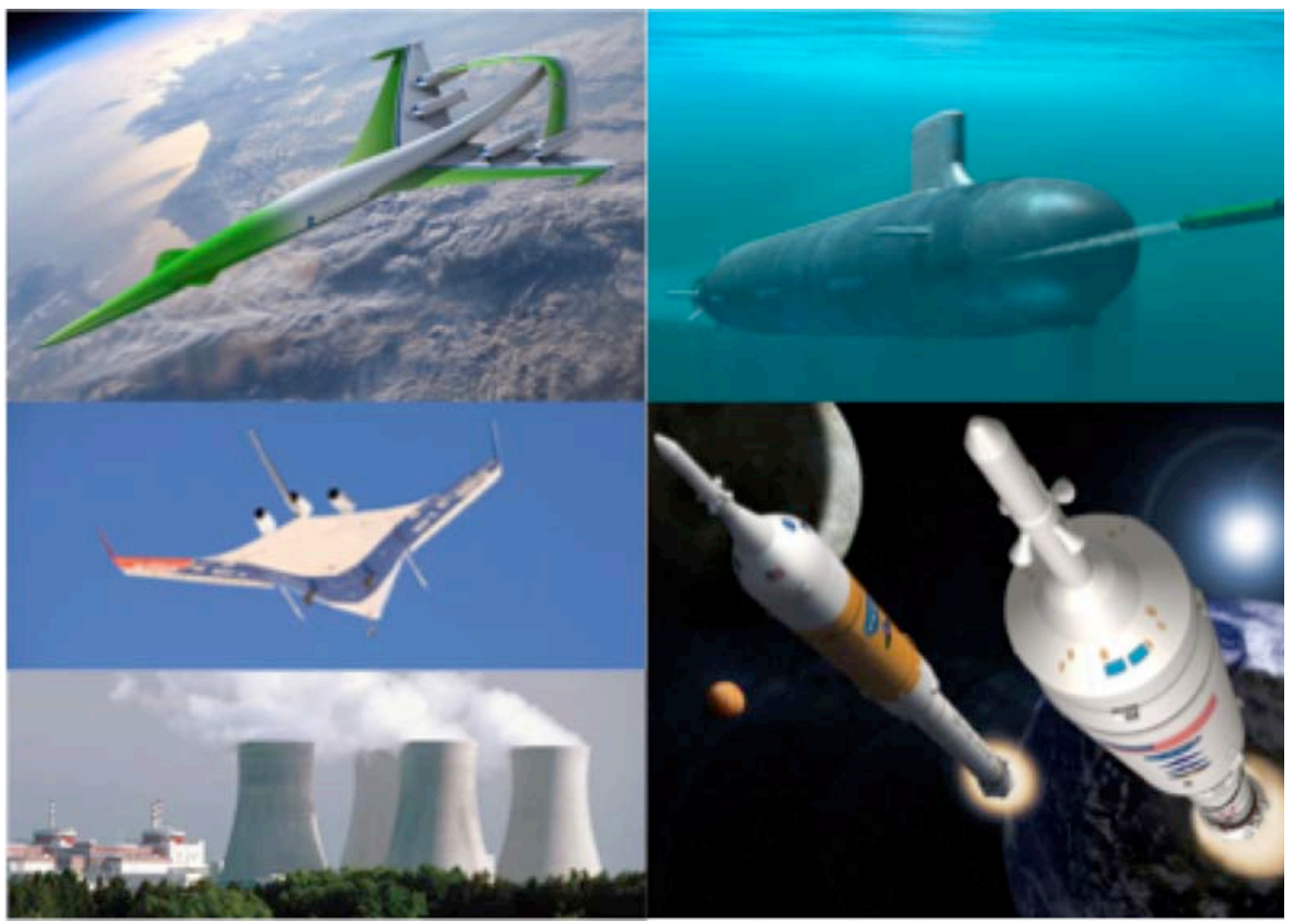

Figure 1 Examples of Large-Scale Complex Engineered Systems

These features of LaCES strain many existing state-of-the-art business and engineering practices. For example, innovative design companies such as IDEO regularly gather their design teams in one room to foster creative solutions, improve communications, and quicken the design cycle. ${ }^{2}$ Practices such as these are arduous, or in some cases impossible, to "scale up" to address the needs of designing a very large system such as a large aircraft. In order to bring together the large, dispersed organizations common to LaCES, current practices include project management, systems engineering, and multidisciplinary design optimization (MDO). However, as engineered systems continue to grow in size and intricacy, these processes are also being strained as design and development timelines and costs continue to escalate. In recent years, the challenges of designing LaCES have given rise to several scientific workshops, identifying new directions in engineering and social science research., ${ }^{3,4,5,6,7,8}$ This genre of design engineering research considers a broad definition of design to incorporate all of the influencing engineering efforts from research through final system testing. However, much of the research on the design of LaCES has necessarily focused on addressing needs in systems engineering, ${ }^{9,}{ }^{10} \mathrm{MDO},{ }^{11},{ }^{12}$ and the social dimensions of system design practices such as decision and game theories. ${ }^{13,14,15,16,17}$

This paper expands on the research on the social dimensions of system design practices focusing on interdisciplinary interactions and organizational theories. We concentrate primarily on the theory of sensemaking ${ }^{18}$ and what this theory may tell us about interdisciplinary interactions in LaCES. These interactions are typically considered during the latter stages of development once a system concept has taken form and the relevant disciplines engage to shape the design. The current work seeks to improve knowledge about interdisciplinary practices focusing on the research and development $(R \& D)$ processes from basic research to early conceptual design. R\&D precedes and overlaps with early design efforts; therefore interdisciplinary interactions during early system design are also included. We use the term $R \& D$ to encompass this entire range of activities. Though the extensive workforce for R\&D represents a diversity of disciplines and may be geographically dispersed, the workforce remains intangibly and inherently connected by their efforts toward the ultimate system. Some of the research questions posed include: What is our current understanding about this system-level connection and the interdisciplinary interactions that shape it? How are the connections made in the large R\&D organizations of LaCES? What is needed to foster these interactions beyond what is currently being exercised in MDO methods? 
Our motivation to explore the interconnectivity of existing R\&D organizations is to better understand how to harness the collective wisdom of the large-scale human system that holds the engineering blueprints of future LaCES that will continue to be a critical part of civilian and military infrastructure. Future LaCES will be required to address the rapidly growing and multifaceted challenges of risk, schedule, budget, workforce, exceptional and resilient engineering performance, as well as much greater efficiency during design and development efforts.

This paper provides a preliminary perspective on some of the organizational influences on interdisciplinary interactions in R\&D based on an empirical study, organizational theory, and the collective experience of the authors in aerospace engineering $\mathrm{R} \& \mathrm{D}, \mathrm{MDO}$, psychology, and design science. This study is an initial examination as part of a broader research effort on interdisciplinarity in the science of designing LaCES. In the next sections, a description of the theoretical framework and research methodology is provided, followed by preliminary analysis and findings. We conclude with potential recommendations and future research plans.

\section{Perspective and Method}

One goal of the current work is to gain a more holistic representation of the interdisciplinary interactions in a research, development, and design setting for extremely large engineered systems. This is achieved by viewing the problem from an interdisciplinary perspective informed by engineering practice as well as social science. Both engineering needs and human behavior, as well as other influences, may shape how interdisciplinary interactions are accomplished. It is possible that the interactions of the teams of people researching and developing LaCES may be reflected within the engineered system. If so, it is important to understand how R\&D teams work on LaCES, and how they can be organized to lead to the best system outcomes.

For the purposes of the present discussion, the following definitions for system relations will be used:

- Cross-disciplinary: All types of interactions between disciplines;

- Multidisciplinary: The non-integrative combination of disciplines, where each discipline preserves its methodologies and assumptions without significant modification from other disciplines;

- Interdisciplinary: Fusing and integrating several disciplines, where each discipline's methodologies or assumptions are interdependent on other disciplines.

Multidisciplinary is distinguished from interdisciplinary to account for the relationship between the disciplines. In a multidisciplinary scenario, the relationship between disciplines "may be mutual and cumulative but not interactive" (Augsburg 2005: 56). In an interdisciplinary relationship, the practices and conventions of each discipline are interactively blended. While multidisciplinary approaches are common today (for example, in MDO), the present study seeks to address the organizational challenges and opportunities for enabling improved interdisciplinary approaches for better system design. In many cases, interdisciplinary approaches do not replace multidisciplinary approaches, but may augment them.

A comprehensive literature review of the many fields of study that are related to the current work is beyond the scope of this paper. Instead, principal areas of literature are reviewed briefly using exemplar literature as references. In the field of engineering, this investigation draws upon research on complex engineered systems including MDO, decision analysis, and systems engineering. In organization science, this work draws on research in sensemaking, highreliability management, positive organizational scholarship (POS), and social network analysis.

Together, these different disciplines informed the creation of the integrative theoretical framework adopted in this research (depicted in Figure 2). This research seeks to synthesize the combined influence of the processes (e.g., MDO) with the people involved (e.g., large distributed workforce), and with the product under development (e.g., aircraft). To ensure this framework is realistic and sensitive to context, an analysis of the unique characteristics of the problem domain (LaCES) was conducted with particular attention to risk levels, existing processes, size or impact of the dispersed organization, and the inherent interdisciplinarity of the engineered system.

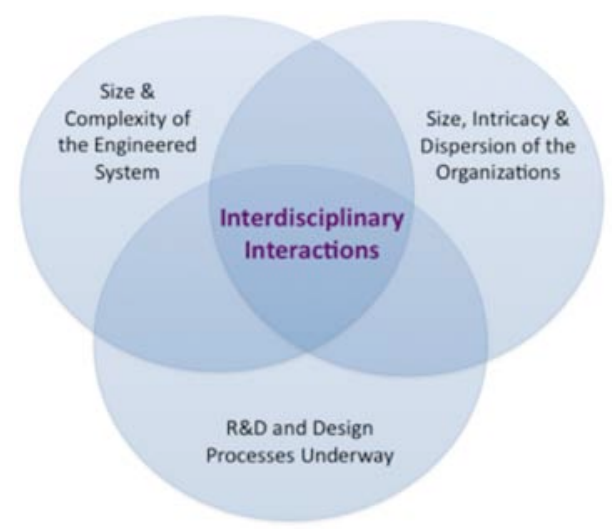

Figure 2 Integrative Theoretical Framework

\section{A. An Organizational Perspective}

An organizational theory, called "sensemaking," ${ }^{18}$ will be used to provide an organizational perspective on some of the challenges and opportunities of interdisciplinary interactions during LaCES R\&D. This theory delves into the 
"micro group levels of analysis" that helps to identify some of the intricate cognitive and social processes required for high organizational performance. ${ }^{19} \mathrm{~A}$ few facets of sensemaking theory are highlighted below to illuminate some of the organizational aspects of interdisciplinary interactions in LaCES R\&D.

As noted by Weick, Sutcliffe, and Obstfeld, "To examine sensemaking is to take a closer look at the context within which decision-making occurs. ${ }^{20}$ Whereas decision making is about strategic rationality (to determine what to do next), sensemaking is about contextual rationality (to make sense of what is happening) ${ }^{21}$ In addition, Pye suggests that an analysis of sensemaking may be "more important than that of leadership because it is more inclusive and draws in other crucial elements of everyday life in organizations which are overlooked by much of the leadership literature.",22

Sensemaking highlights the influence of identity and social context in organizations. For example, in interdisciplinary interactions, identity may become less clear. A LaCES researcher may ask: Who am I in this "between departments" world? Social context is also ambiguous and perhaps intimidating during interdiscipline R\&D where employees are not certain how to be credible with, or even respected by, unfamiliar departments.

The theory of sensemaking also distinguishes two information-processing scenarios in organizations: uncertainty and ambiguity. Just as uncertainty has been a common focus in MDO research in engineering for several decades, psychologists and organization theorists have studied uncertainty in the social sciences since the mid-20 $0^{\text {th }}$ century. ${ }^{23}$ The two perspectives on uncertainty resonate. In organization theory, the definition of uncertainty is the absence of information, where one seeks answers to explicit questions. ${ }^{23}$ In engineering, uncertainty similarly deals with lack of knowledge and the often unpredictable difference between what data is available and what is needed to confirm predictions. In engineering, statistics and probability may be used to help reduce uncertainty. Ambiguity (or equivocality), on the other hand, is primarily discussed in organizational theory research and deals with a lack of understanding or confusion that is common in organizations where "participants are not certain about what questions to ask, and if questions are posed, the situation is ill-defined to the point where a clear answer will not be forthcoming (March and Olson 1976). ${ }^{23}$

High levels of both uncertainty and ambiguity exist in conducting research, development and early design of LaCES, and the inherent interdependence (and hence interdisciplinarity) between disciplines places further challenges on information processing needs. For example, during interdisciplinary interactions, the amount of information one receives greatly increases, however, there are both "multiple and conflicting interpretations" 23 of this information that create confusion and a lack of clarity. One example of this is multiple disciplines using the same words to define different concepts and, the same parameter may have very different levels of importance in each discipline. Whereas additional, specific data helps to address uncertainty, problems and priorities need to be defined help to address ambiguity. Figure 3 shows the different communication styles and organization practices for addressing uncertainty and ambiguity. ${ }^{23}$ Sensemaking theory suggests that a balanced approach to information processing is needed to foster interdisciplinary interactions such that both high amounts of numeric data via less personal media is received as well as high amounts of face-toface time via more personal media.

The importance of several active and adaptive organizational concepts is also woven through much of the literature on sensemaking. Concepts such as improvisation, flexibility, updating, and continual input to keep what you have obtained within the organization are repeated in several papers (Blatt, et al., ${ }^{19}$ Maitlis, et al., ${ }^{24}$ Weick and Roberts ${ }^{25}$, Schulman, ${ }^{26} \mathrm{Pye}^{22}$ and others). The disintegrative nature of other key organizational properties, such as attention, close coordination, and mutual trust, is often noted. ${ }^{27}$ Starbuck and Nystrom, summarize by stating: "A
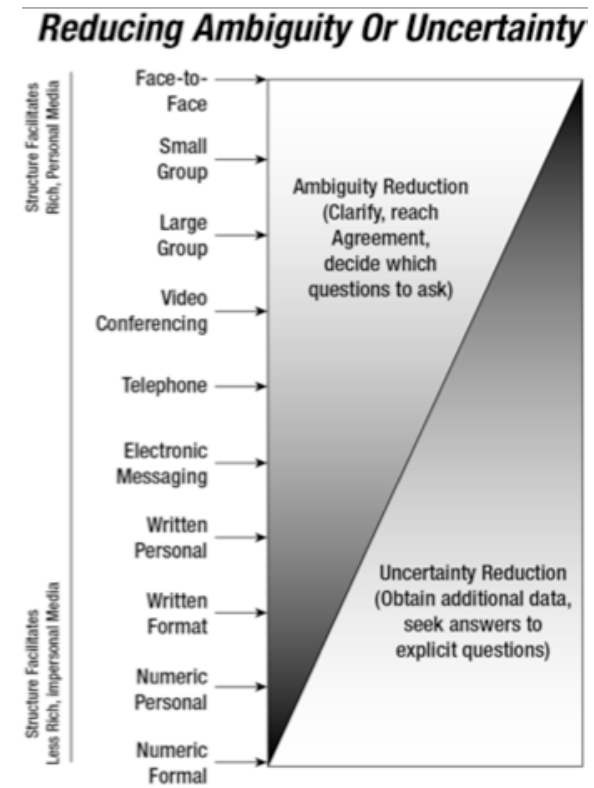

Figure 3 Communication Styles for Ambiguity or Uncertainty, from Daft, 1993 well-designed organization is not a stable solution to achieve, but a developmental process to keep active. ${ }^{28}$ From an organizational perspective, progressing from multidisciplinary $\mathrm{R} \& \mathrm{D}$ (where there is a presence of multiple disciplines) to interdisciplinary $\mathrm{R} \& \mathrm{D}$ (where the disciplines begin to amalgamate) may begin with meetings of multiple disciplines but it continues to progress and sustain itself with active engagement between the participants to integrate their work. Further, the participants will likely need to be 
flexible in their use of labels and will need to improvise solutions to newly defined, and ill-defined, problems that exist between the disciplines.

Concepts of improvisation and flexibility are also central to research on high reliability organizations (HROs) - a genre of research with foundations in sensemaking theory. Work by Sutcliffe and Weick on HROs suggests that adaptively organizing for increasingly complex environments is necessary, as opposed to using static organizational structures. ${ }^{29}$ Their work focuses on organizations that operate in high-risk scenarios such as aircraft carrier operations, air traffic control, and fire fighting. Sutcliffe identifies the following characteristics of HROs:

- Operate in an unforgiving social and political environment,

- Use complex processes to manage complex technologies (the potential exists for surprises and adverse consequences),

- Have limited opportunities for learning through experimentation, and

- Have widespread accountability with sanctions for substandard performance. ${ }^{30}$

Roberts also notes that another key characteristic of HROs is "extreme interdependence," and that "HROs are characterized by both advanced technology (requiring specialist understanding) and high degrees of interdependence (requiring generalist understanding). ${ }^{31}$

Though R\&D and operations are two very different facets for LaCES, Sutcliffe's summary of the characteristics of HROs (which operate some LaCES) is largely appropriate for organizations that research, develop, and design LaCES as well. As Schulman, 2004, points out "these systems due their complexity are formally underdetermined; that is, they are capable of assuming more conditions or system states than can be planned for or anticipated in formal designs [and $R \& D$ ]. This means they have the capacity to confront managers [and researchers] with problems of high variety and significant novelty" (emphasis added). Another example where R\&D of LaCES mirrors HROs is in the area of large-scale testing and evaluation, where "the consequences and costs associated with major failures in some technical operations are greater than the value of the lessons learned from them. ${ }^{32}$ Further, this results in "an organizational process colored by efforts to engage in trials without errors, lest the next error be the last trial. ${ }^{, 32}$ The research on HROs and their similarities to the present study suggests a necessary tension in interdisciplinary interactions in LaCES. This tension implies there should be a continual appreciation of the persistent uncertainties and ambiguities that exist (a pessimistic attitude about failure) while assiduously seeking ways to illuminate them (adapting roles, forging new communication paths, and improvising on the spot).

Another aspect of sensemaking theory that is relevant to interdisciplinary interactions is the concept of "interrelating" that is discussed in Weick's research on "collective mind." ${ }^{, 25,29}$ This work addresses the cognitive processes of a group that must heedfully work together to achieve a solution, and hence, provides a useful organizational perspective concerning the collective nature of interdisciplinary R\&D. Just as in R\&D of LaCES, there is a "transindividual quality of collective mind. Portions of the envisaged system are known to all, but all of it is known to none. ${ }^{25}$ The organizational perspective of collective mind focuses attention more on active processes (or how things are being done) over an outcome (or what things are done). For example, Weick portrays "collective mind in terms of method rather than content, structuring rather than structure, connecting rather than connections. Interrelations are not given but are constructed and reconstructed continually by individuals (Blumer, 1969: 110) through ongoing activities of contributing, representing, and subordinating." ${ }^{25}$ This perspective suggested a focus on the processes of interdisciplinary interactions as well as the products of these interactions.

In conceptualizing the collective mind, Weick notes that there is "little room for heroic, autonomous individuals. A well-developed organization mind, capable of reliable performance is thoroughly social. It is built of ongoing interrelating and dense interrelations. Thus, interpersonal skills are not a luxury in high-reliability systems. They are a necessity." Thus, from an organizational view, interdisciplinary interactions may be built on similar "ongoing interrelating and dense interrelations," which ties to the diverse information processing needs mentioned earlier. Other requisite skills are defined in the concept of collective mind that may relate to skills needed for interdisciplinary interactions: "narrative skills (Bruner, 1986; Weick and Browning, 1986; Orr, 1990) are important for collective mind because stories organize know-how, tacit knowledge, nuance, sequence, multiple causation, means-end relations, and consequences into a memorable plot.. ${ }^{25}$

The organizational perspectives on interdisciplinary interactions from sensemaking theory is combined with engineering perspectives from practitioners (and the authors) in the current work to gain more insights into problems and promise of interdisciplinary interactions during R\&D of LaCES. The research method included blending theory and preliminary empirical data in a qualitative approach.

\section{B. Research methodology}

In order "to describe and conceptualize the variety that exists within the subject under study" 33 surveys with experts in LaCES were conducted. Inductive qualitative analysis of the data is being used, drawing heavily from 
grounded theory and constant comparative methods. There are a large number of references that describe these methods, for example, references ${ }^{33}$ through ${ }^{39}$. Though commonplace in the social sciences, qualitative methods are less frequently used in the field of engineering. In some sense, qualitative analysis further defines the many facets of a problem before attempting to solve it quantitatively. "The broad purpose of qualitative research is to understand more about the human perspectives and provide a detailed description of a given event or phenomenon" 34 and "for understanding the world from the perspective of those studied (i.e., the informants); and for examining and articulating processes." 39 As such, qualitative research is sensitive to context and takes a holistic perspective that includes the social, historical, and temporal contexts. ${ }^{34}$

In qualitative research, the researcher is inherently a part of the research and its interpretive findings. For this study, the knowledge and experience of the lead author in aerospace R\&D (20+ years) is significant, as it represents an insider perspective on the subject of study. "Insider research refers to when researchers conduct research with populations of which they are also members (Kanuha, 2000) so that the researcher shares an identity, language, and experiential base with the study participants (Asselin, 2003)," ${ }^{, 40}$ (see also reference ${ }^{41}$ ). One study notes: "As is clear, there are costs and benefits to be weighed regarding the insider versus outsider status of the researcher. Being an insider might raise issues of undue influence of the researcher's perspective, but being an outsider does not create immunity to the influence of personal perspective. Furthermore, although there might be caveats to being a member of the group studied, for many access to the group would not be possible if the researcher was not a member of that group. The positive and negative elements of each must therefore be carefully assessed." 40 For the current study, personal experience was critical in gaining access to data and understanding nuances of meaning. To reduce experimenter bias, peer examination (from those within and outside of aerospace) was used to cross check interpretations. Member checking was also utilized by obtaining feedback on the findings from study participants. Triangulation is also inherent in the research design by collecting data from multiple forms (surveys, interviews, and ethnography) and using multiple organizational theories. As noted previously, the current report focuses on preliminary analysis of a survey together with sensemaking theory.

The written survey was conducted at the NSF/NASA Workshop on Large-Scale Complex Engineered Systems, From Research to Product Realization. ${ }^{5}$ The goal of this survey was to provide an assessment of current perspectives regarding interdisciplinary interactions during $\mathrm{R} \& \mathrm{D}$ of LaCES. The senior leaders and researchers invited to participate in the workshop provided a convenience sample of a rare participant pool. The 62 survey respondents represented a wide variety of backgrounds and extensive experience in engineering, including practicing researchers, project leaders, systems engineers, and senior executives in industry and government, as well as leading academic researchers in engineering design, organization science, optimization, and economics. The respondents (most of whom did not know each other) also represented a wide variety of organizations from different government agencies, corporations, and universities. The sample size is significant considering the difficulty of garnering responses from a multidisciplinary group of LaCES experts from different organizations. While these participants are selected based on their prior experience with R\&D for LaCES, there was no intent to claim a representative sample of engineers for this study. Rather, this group was selected because they are in the position, based on their personal experience, to provide their perceptions of R\&D within LaCES.

The survey was designed to include simple instructions for obtaining short, written answers to seven open-ended questions. The written instructions printed on each survey were: "Please consider your first-hand experiences with research in large-scale, complex engineering systems." These instructions were followed by seven questions:

1. How important do you think interdisciplinary interactions are for complex systems?

2. Please describe the potential benefits to interdisciplinary interactions.

3. Please describe the potential negatives to interdisciplinary interactions.

4. Please describe things that encourage interdisciplinary interactions.

5. Please describe the obstacles to interdisciplinary interactions.

6. Please provide some background context for your experience:

- Where do you work?

- What do you do for your occupation?

- How many years of work experience do you have?

7. Please add any other comments you wish below:

The participants completed the survey on site within a 30 minute window. The responses received provided participants' insight into current interdisciplinary interactions practices in R\&D for LaCES. Conducting the survey at a workshop focused on LaCES also ensured that the responses were sensitive to this context. Understanding the nuances and other characteristics of the LaCES domain proved vital to properly interpreting the responses received. The participants reported a wide variety of experiences with LaCES throughout their careers. For example, some responses were brief, noting that interdisciplinary interactions enable "fewer surprises" or were "time consuming." 
Other responses were more elaborate such as: "Interactions between disciplines develop perspective within each discipline to respect the issues and potential repercussions of decisions;" and, "It takes time to sort out differences in language, areas of common interest, and to develop mutual respect and appreciation for what each brings to the table." In analyzing the data from the survey, repetitions, similarities, and differences of concepts were considered, being mindful of each individual respondent's answers as a whole.

\section{Preliminary Analysis}

The size, geographic dispersion, and immensity of the engineered system create both needs and challenges for interdisciplinary interactions in the research and development of LaCES. The blending of numerous technical disciplines is well developed in MDO methods today, where models from different disciplines are integrated into a rigorous mathematical system framework. As aforementioned, the current study delves into the interdependence of the disciplines and the associated interactive practices between the researchers and the implications for the greater organization. The dotted lines in Figure 4 depict the focus of the current work.

While most of the responses to the questions were multi-faceted, the responses considering the importance of these interactions were overwhelmingly (and surprisingly) consistent among nearly all respondents. The responses noted that interdisciplinary interactions were of high importance with most respondents using strong descriptors such as "essential, critical, very, extremely." The consistency of responses suggests that a high value is placed on interdisciplinarity in the R\&D of LaCES. At the same time, the responses indicated significant challenges in implementation. Remarkably, the vast majority of noted challenges in implementation

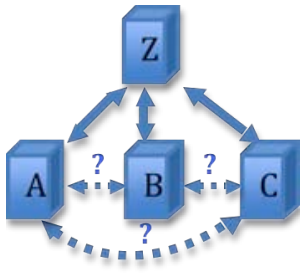

Figure 4 Schematic Depicting CrossDisciplinary Interactions were not directly related to engineering or mechanical issues. Rather, problems related to organizational and human dynamics and time were mostly commonly noted. From a closer examination of the engineered system, its related human and organizational system, and the survey responses, several themes emerged. For the present discussion and preliminary analysis, two of the over-arching themes from the survey responses will be examined. These are related to efforts toward collective knowledge and organizational structure. These themes are closely coupled as is discussed below.

\section{A. Efforts Towards Collective Knowledge}

The responses concerning the benefits of interdisciplinarity interactions in R\&D focused on innovation and creativity; learning and improved system understanding; and problem mitigation. These benefits appear to be linked. For example, the "broader understanding, shared knowledge, emerging thoughts" noted in some of the responses provide the additional awareness needed to enable innovation and mitigate problems by reducing "'downstream surprises' of 'emergent behaviors' from un-modeled interactions," noted by another respondent. Innovation and creativity was noted by many respondents that cited opportunities for "new technical solutions," "unforeseen capabilities," and "diversity of thought." The benefit of learning and improved understanding was articulated by survey respondents as: "recognizing trades and impacts that cross discipline boundaries;" "better view and perspective;" "understanding the multiple domain problems;" "discovery learning;" and "understanding of the true interfaces."

A key characteristic of LaCES is the often-unknown number of interdependencies within the system or couplings. Although the vast majority of these couplings are well understood, tested, and documented, comprehensive awareness and understanding of all interactions within the system is not feasible for larger complex engineered systems. Correspondingly, exhaustive understanding of all facets of the system is beyond the comprehension of any one individual or small team. Rather, exhaustive understanding of the system is held by the collective knowledge of the organization as a whole rather than by a group of senior leaders. This collective organizational knowledge is both explicit (and usually documented), as well as tacit, and transmitted through less formal and undocumented means, if at all.

The inherently social nature of both tacit knowledge sharing and developing a collective organizational mind that strives to "see" the greater system gives rise to the most commonly referenced topic in the survey responses: namely communication challenges. Respondents noted repeated challenges related to language, terminology, and vocabulary when interacting across disciplines. Sample responses cited by several respondents included: "disparate levels of understanding of other disciplines;" "misunderstanding between people of different backgrounds with different terminology;" "break down in communication;" and, "communication barriers." Communication challenges are 
likely linked with other challenges in interdisciplinary interactions noted by respondents, specifically, additional time requirements, confusion, and disorderliness.

These responses appear to correlate with the need for narrative skills in grasping for a collective perspective on the system. Research on the development of a collective mind notes that: "narrative skills (Bruner, 1986; Weick and Browning, 1986; Orr, 1990) are important for collective mind because stories organize know-how, tacit knowledge, nuance, sequence, multiple causation, means-end relations, and consequences into a memorable plot." ${ }^{25}$ Such narrative skills foster a reduction in confusion and disorder by providing clarifications, values, and priorities. As noted in sensemaking theory, these challenges are tied to issues related to ambiguity where one is faced with a lack of clarity and multiple meanings for the data at hand. To address ambiguity, communication must become increasingly interpersonal, as depicted in Figure 3.

Correspondingly, survey respondents indicate that interdisciplinary interactions were encouraged when there were opportunities to build "working level relationships" such as "informal outings." One respondent noted: "opportunity for informal interception to build trust, respect for other colleagues." Many in the survey reiterated the need for respect and trust to encourage interdisciplinary interactions.

In aggregate, the responses relating to gaining a better system understanding, reducing confusion, diversity of thought, trust, respect, and building relationships indicate efforts toward developing a collective organizational mind, where these characteristics are common. As noted in the sensemaking literature, these organizational characteristics also enable the reliability of the engineered system to increase. Studies of organizations that successfully and reliably operate high-risk systems such as LaCES show that these organizations tend toward a collective mind, and what is referred to as "heedful interrelating" within the organization. If interdiscipline interactions are driven by a need to interrelate as suggested by best practices in the sensemaking literature then:

- Ambiguity must be addressed in addition to uncertainty;

- Tacit knowledge in addition to explicit knowledge;

- The social construction of knowledge in addition to the numerical construction of a system model;

- The organizational implementation of interdisciplinary approaches in addition to the mathematical implementation of multidisciplinary approaches; and

- Sensemaking in addition to decision making.

This collective view also suggests that, in some sense, an interdependent R\&D organization necessarily must function closer to that of a symphony (or a living organism) of many diverse but intertwined, interdependent parts rather than an assembly line (or mosaic) of diverse but joined, independent parts. The former is the hallmark of complex systems, where the system is not reducible to the sum of its parts.

The "thoroughly social" nature of a well-developed collective mind was a theme that appeared throughout the majority of survey responses. Some examples of social characterizations include: "tolerance," "openness," "group think," "disinterested teammates," "mixing groups," "team member familiarity," "conflicting objectives and preference," "mitigating discipline biases," "ideological arguments," and "cultural attitude." The latter response ("culture") was noted repeatedly in the context of both individuals and organizations. Culture was often noted as a means of fostering as well as impeding interdisciplinary interactions.

Other obstacles impeding interdisciplinarity and related collective knowledge development related to emotion, including several, very descriptive single word responses such as "fear," "ignorance," "tribalism," "arrogance," "elitism," and "pride." Some of these responses suggest a defensive reaction in interdisciplinary interactions. Another theme from the responses about the negatives of interdisciplinary interactions was a tension between the desire to avoid reducing the focus of single-discipline research and to avoid the dominance of any single discipline. The "turf battles" noted by one respondent may be a source of interference for interdisciplinary interactions and related collective mind development, the latter of which is fundamentally "tied together by trust." 25

\section{Organizational Structure}

As departments and specialty areas interact, coordination and communication becomes increasingly challenging, particularly given the strongly hierarchical organizational styles of most LaCES organizations. As with the development of many complex systems, the research, development, and design processes are often organized by a decomposition of the system into smaller, simpler, and more manageable sub-systems. These sub-systems may be functional decompositions of the engineered system, such as wing, engine, etc., or they may be disciplinary such as aerodynamics, structures, etc., or any number of other groups. These decompositions are employed by the systems engineering and MDO communities to frame the system development processes.

However, regardless of the method of decomposition used, each "cut" in decomposition creates boundaries between departments, disciplines, requirements, mathematical models, assumptions, knowledge domains, incentives, 
and other factors. Knowledge management across boundaries is a known problem in the organizational science literature. One example reference is the work by Carlile whose work integrates three different perspectives on boundaries: knowledge as "a thing to store and retrieve," "the importance of a common meaning to share knowledge between actors," and "how different interests impede knowledge sharing." Carlile further explores the "negative consequences of the path-dependent nature of knowledge" in settings where innovation is desired. ${ }^{42,43}$

Historically, connections between sub-systems or elements of a large complex system are data driven using extensive documentation, MDO methods, and design methods such as quality function deployment. ${ }^{44}$ Organizationally, cross-department connections are generally made through a hierarchical construct of research and design reviews and other forums where diverse teams are encouraged to assemble. Several survey respondents noted that opportunities such as these cross-discipline events (as well as workshops) assist in encouraging interdisciplinarity in R\&D.

In the survey, organizational structure, processes and incentives also ranked as dominant enablers for interdiscipline interactions in R\&D. Suggested organizational structures that were enablers included "integrative teams" such as integrated product teams and structures that were not "stove piped" or "discipline-based." Pointedly, negative correlations of these topics were also mentioned as dominant obstacles. Suggested obstacles related to organizational structure also centered on restrictions resulting from the common functional or discipline based structure of R\&D organizations in LaCES. The survey respondents often mentioned addressing the organizational "isolation," and "distance" by fostering "co-location."

To illustrate these points, a simple analogy is employed. Consider the following system challenge: Conduct research on (or design) a lamp. The organization doing the work may set up a typical hierarchical organization (depicted in Figure 5) where a company senior executive is responsible for the overall effort at the system level, which for this simple analogy is a lamp. The next level of the organization is arranged by parts of the lamp (shade, bulb, stem, and base). Each suborganization is headed by a respective "part director." Each "part" organization is comprised of a group of engineers and scientists that address each aspect of the lamp development as organized. Within each part group, R\&D is conducted and technology advancements made. For

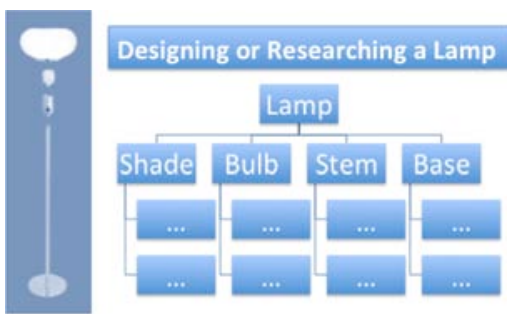

Figure 5 Demonstrative Analogy example, improved filaments come from the bulb group and enhanced shade materials are developed by the shade group, etc.

Yet, consider that one of the high performing system solutions uses an illuminating shade, exclusive of a separate bulb, or, an illuminating stem, exclusive of a separate bulb (depicted in Figure 6). Attaining this unconventional concept, or others that do not naturally derive from the traditional discipline experience, is extremely difficult or impossible given the organization defined. In this example, the organization serves as a constraint on the final system development. Hence, the organization can dictate the form of the resulting engineered system and limit the types of system designs created. In a sense, this situation corresponds to the still elusive general problem in design: While we excel at refining and optimizing existing configurations (or system topologies), we have very few good ways to create new configurations or topologies - almost always relying on human creativity (frequently cited as a key benefit of interdisciplinary interactions).

To address this problem, specific organizational strategies have been created and widely applied, such as:

1) Increasing the interaction of the "part directors;"

2) Hiring a systems engineer or optimization specialist;

3) Further decomposing the parts of the lamp and increasing the detail with which the requirements or objectives are stated; and,

4) Requesting that all scientists and engineers document their findings on a knowledge management database.

Each of these strategies may provide important improvements. Several respondents in the survey noted experiences related to Strategy 1 above, saying that it was important to have leadership and management model the desired interdisciplinary interactions for their teams. Only two respondents mentioned Strategy 2. No respondents mentioned the other two

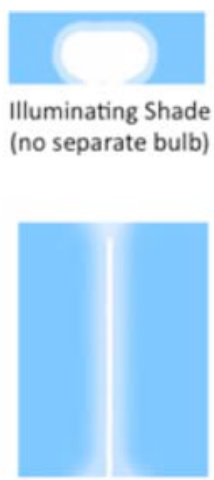

Illuminating Stem (no separate bulb) Figure 6 Example Innovative Concept strategies (3 and 4). Implementing any these strategies (and possibly others) without further complementary actions, such as addressing the communication challenges, will likely fall short of addressing the social or human connectivity needed to drive the organization toward an unconventional solution. Interdisciplinary 
interactions are often augmentative rather than exclusive to existing engineering practices; and, they are not automatic.

The lamp analogy also illustrates how the engineered system concept is a function of the organizational structure and practices, and vice versa. The engineered system is also a function of the initial problem formulation, which is often accepted as given rather than researched or designed. In the example provided, the challenge may have alternatively been stated: "Illuminate the room." In addition, even with the simplest engineered systems (e.g., a lamp), systematically linking together well-known components may not achieve the system configuration or performance desired, regardless of the quality of work on the components. Many researchers state that most innovation happens at the boundaries between disciplines or specializations (e.g., ref $^{45}$ ).

In examining innovative design companies, studies have pointed out that these companies necessarily adopt adaptive organizational styles. ${ }^{7}$ Innovation is challenging within highly structured bureaucratic organizations, which are common in LaCES R\&D. For example, Anconda discusses the distributed leadership styles of several companies with a more flexible yet organized leadership style that fosters creativity. ${ }^{46}$ Quinn describes the adaptive organizational styles in companies as a "competing values framework," where different organizational styles are needed for different outcomes. Specifically, bureaucracy is needed for control, and adhocracy for learning and innovation, for example. ${ }^{47}$

As noted earlier, adaptively organizing is also tied to increasing the reliability in high risk and complex environments in systems such as LaCES. In HROs, improvisation and flexibility are critical for the organization and its related roles and interactions due to the dynamic nature of complex engineered systems. Roe and Schulman report that "reliability is not the outcome of organizational invariance, but, quite the contrary, results from a continuous management of fluctuations both in job performance and in overall departmental interaction. It is the containment of these fluctuations, rather than their elimination, that promotes overall reliability." ${ }^{27}$ Hence, several researchers suggest that HROs should emphasize organizing rather than organization. One may argue that the vast majority of organizations that do LSCES R\&D emphasize a static organization rather than adaptive organizing. Organizations are largely fixed; R\&D engineers generally remain in one part of the organization for most of their careers. In fact, employees often meet organizational change with reluctance and even dread; and, managers often meet organizational flexibility with sincere concern.

\section{Discussion}

The survey responses clearly indicate that interdisciplinary interactions are very important. Noted benefits of innovation and creativity, broader system awareness, learning, and problem mitigation are substantial contributors to improving the development, design, and performance of engineered systems as well as potentially reducing costs and time. Given that LaCES are costly, take years to complete, and operate under extreme conditions, these benefits are quite significant. However, it is interesting to note that each of these benefits is realized in the longer term. Responses related to short term benefits of interdisciplinary interactions were very minimal. The significant obstacles in implementation mentioned suggest that the path toward enabling interdisciplinary interactions is challenging and deeply multi-faceted (with no quick fixes). Communication challenges must be addressed, office locations connected, cultures must be altered, confusion reduced, incentives recast, timelines and tasks reconsidered, emotions heard, organizational structures adapted, and leadership rethought.

Based on the survey, the importance and benefits of interdisciplinary interactions in developing large-scale systems is evident. However, given the challenges of implementation, the next questions may be: When are they important, to what extent, and, how do we implement them? Common approaches today in LaCES organizations seem to focus on improving software tools and simulation models and adding or revising oversight, requirements, or documentation. Notwithstanding, the survey responses and the social science literature resoundingly suggest alternative and augmentative approaches that address the social and organizational challenges to enable effective interdisciplinary interactions.

As engineered systems have continued to grow in cost, development time, technical risk, societal reliance, and connection with other systems, there is a need to further expand our approaches to more aptly address the growing challenges. These challenges include non-engineering factors that may heavily influence, and even constrain, the design and performance of the engineered system. The human system in the organization seems to steer the engineered system. Our preliminary analysis also suggests that enabling successful interdisciplinary interactions requires interdisciplinary problem formulation and solutions. These may include researching, developing, and designing the engineered system as well as the teams, organizational structures and processes, incentives, jobs, office spaces, training, and other aspects of the greater "system." Questions remain regarding which of these 
organizational aspects offer the most benefit for a particular system design effort as well as when to design them, to what extent, and how to implement these changes within an existing large organization.

To explore one example of designing a potential new organizational role to foster interdisciplinary interactions, let us reconsider the lamp analogy depicted earlier. One approach toward fostering connections that may lead to the innovative solutions suggested may be establishing and then facilitating regular interactions between the engineers with deep discipline knowledge in each lamp part group. This would require inner-connectivity at lower levels in the hierarchy (whereas a hierarchy typically promotes inner-connectivity mostly at the higher levels). Though simple in concept, implementation of this approach has several considerations. As noted in the research on HROs, deep specialist knowledge is required as well as generalist knowledge in organizations that work with high-risk systems. While deep specialty knowledge is vital for LaCES, weaving together the deep knowledge bases is also vital. Achieving this balance will largely entail carefully "horizontally weaving" through existing hierarchical organizations (where communication paths are largely vertical in the hierarchy). This approach seeks not to eliminate deep discipline knowledge but to interrelate it, which may help to more fully capitalize on specialty knowledge. Achieving this balance may also address the single-discipline tension noted in the survey responses (avoiding loss of single-discipline focus while avoiding single-discipline dominance).

Further exploring the potential task of a "horizontal weaver" suggests that such a role would require using engineering skills honed in more than one area (structures, controls, propulsion, etc.), as well as social science skills honed in more than one area (negotiation, story-telling, motivation, building positive social capital, network science, etc.). The hypothetical work of the "horizontal weaver" is necessarily beyond organizational "glue," for it would require addressing the considerations for sensemaking and developing a collective organizational mind such as: reducing ambiguity, developing relationships built on trust and respect, and welcoming diversity of thought.

As a starting point, the "horizontal weaving" role would need to serve as an ongoing forcing function in the organization since steady state is a naïve assumption in organizational dynamics. This forcing function would need to enable synergistic knowledge sharing that connects tacit knowledge, ideas, language, assumptions, and preferences across organizational and knowledge boundaries. These "horizontal weavers" likely will need to create and facilitate dynamic and iterative communication pathways where necessary. Other literature refers to comparable organizational roles and skills, such as: 1) the "connectors, mavens, and salesmen" described in Gladwell's The Tipping Point; ${ }^{48}$ 2) the "energizers" described in POS literature by Baker; ${ }^{49,50}$ and 3) the highly desired "deep generalists" described by McMasters of Boeing. ${ }^{51,52}$

Designing new job descriptions and incentives may also be necessary. For example, employees not hired exclusively to be an expert in one area, but to use their expertise to work with other disciplines to enable a systems solution. In this latter scenario, career advancement is not contingent upon one's progression in their discipline expertise alone but also, or instead, career advancement could hinge on one's ability to heedfully interrelate with other disciplines - a thoroughly social endeavor, as noted in the sensemaking literature. This effort would entail augmenting traditional MDO and systems analysis efforts to include addressing many of the human and organizational challenges noted. Whereas the necessity of interpersonal and narrative skills for higher-ranking individuals in organizations is well established, pushing this necessity to lower levels in the organization is paramount for aptly enabling interdisciplinary interactions.

Further studies that explore other aspects of organization science will likely yield additional understanding and recommendations for LaCES. Future efforts in the current research will examine additional data from the survey and responses from interviews with practicing R\&D engineers in LaCES. In addition, future work will encompass other genres of organizational science literature such as positive organizational scholarship (POS) and social network analysis.

\section{Conclusion}

As the practice of engineering continues to develop increasingly larger, more expansive, and interconnected systems that provide critical capabilities, understanding how immense teams of individuals interface to connect engineering interfaces in a system concept has become central to producing an advanced LaCES on schedule, within budget, and with the precise engineering performance required. The coupling between the engineered system and its human organization is rarely adequately appreciated. The current study explored interdisciplinary interactions in R\&D striving toward a more holistic perspective that incorporated the engineering and organization coupling. This approach was adopted to better understand how to more effectively harness the collective wisdom of the engineers and scientists that research and develop LaCES to foster greater innovation and performance in the engineered system while reducing the cost and time of development. 
This paper provided preliminary analysis of some of the challenges and opportunities in enabling interdisciplinary interactions in LaCES R\&D using an organizational perspective based on sensemaking theory and qualitative analysis of data from a survey given to LaCES experts. Our preliminary analysis indicated that interdisciplinary interactions might be highly valued and offered benefits such as innovation and problem mitigation. However, implementation challenges focused on organizational and human dynamics such as communication difficulties and organizational structure and culture. These challenges also present areas for improvements where aspects of the organization may be proactively designed with the engineered system in mind. Our analysis also indicated that interdisciplinary interactions may foster efforts toward building collective knowledge in an organization. Elements of the coupling between the organization structure and engineering practice was also discussed noting that the former may constrain the latter.

Fundamentally, this preliminary analysis shows that enabling interdisciplinary interactions in LaCES R\&D warrants an interdisciplinary approach (engineering and social science) that augments traditional multidisciplinary approaches to address the integration of people and their ideas as well as the integration of engineering constructs such as computer models.

\section{Acknowledgements}

The authors wish to acknowledge the helpful contributions of Professors Wayne Baker, Shanna Daly, Karl Weick, Robert Quinn, and Richard Gonzalez, from the University of Michigan; Professor Christina Bloebaum, from Iowa State; Drs. Steven McKnight and George Hazelrigg from NSF; Professor Paul Collopy from the University of Alabama; Ms. Vicki Crisp from NASA Langley; and, Professor Dianne DeTurris from California Polytechnic State University.

\section{References}

1JPDO. "http://www.jpdo.gov." 2012.

${ }^{2}$ IDEO. "http://www.ideo.com." 2012.

${ }^{3}$ Deshmukh, A., and Collopy, P. "Fundamental Research into the Design of Large-Scale Complex Systems." 2010.

${ }^{4}$ Bloebaum, C. L., and McGowan, A. M. R. "Design of Complex Engineered Systems," Journal of Mechanical Design Vol. 132, 2010, p. 120301.

${ }^{5}$ Bloebaum, C. L., Collopy, P., and Hazelrigg, G. A. "NSF/NASA Workshop on the Design of Large-Scale Complex Engineered Systems - From Research to Product Realization," 12th AIAA Aviation Technology, Integration, and Operations (ATIO) Conference and 14th AIAA/ISSMO Multidisciplinary Analysis and Optimization Conference. AIAA, Indianapolis, Indiana, 2012.

${ }^{6}$ Bloebaum, C. L., and McGowan, A.-M. R. "The Design of Large-Scale Complex Engineered Systems: Present Challenges and Future Promise," 12th AIAA Aviation Technology, Integration, and Operations (ATIO) Conference and 14th AIAA/ISSMO Multidisciplinary Analysis and Optimization Conference. AIAA, Indianapolis, IN, 2012.

${ }^{7}$ Ben-Ari, G. Organizing for a complex world: developing tomorrow's defense and net-centric systems: Center for Strategic \& International Studies, 2009.

${ }^{8}$ Rouse, W. B. "Complex engineered, organizational and natural systems," Systems Engineering Vol. 10, No. 3, 2007, pp. 260-271.

doi: $10.1002 /$ sys. 20076

${ }^{9}$ Boehm, B., and Jain, A. "A value-based theory of systems engineering." 2006.

${ }^{10}$ Griffin, M. D. "How do we fix System Engineering?," 61st International Astronautical Congress. Vol. IAC10.D1.5.4, Prague, Czech Republic, 2010.

${ }^{11}$ Simpson, T. W., and Martins, J. R. R. A. "Multidisciplinary Design Optimization for Complex Engineered Systems: Report From a National Science Foundation Workshop," Journal of Mechanical Design Vol. 133, 2011, p. 101002.

${ }^{12}$ Collopy, P., Bloebaum, C. L., and Mesmer, B. L. "The Distinct and Interrelated Roles of Value-Driven Design, Multidisciplinary Design Optimization, and Decision Analysis," 12th AIAA Aviation Technology, Integration, and Operations (ATIO) Conference and 14th AIAA/ISSMO Multidisciplinary Analysis and Optimization Conference. AIAA, Indianapolis, Indiana, 2012. 7820,2007

${ }^{13}$ Collopy, P. "Adverse impact of extensive attribute requirements on the design of complex systems," AIAA paper Vol.

${ }^{14}$ Hazelrigg, G. A. Fundamentals of Decision Making for Engineering Design and Systems Engineering: George A Hazelrigg, 2012.

${ }^{15}$ Matheson, J. E., and Abbas, A. E. "Utility transversality: a value-based approach," Journal of Multi-Criteria Decision Analysis Vol. 13, No. 5-6, 2005, pp. 229-238. 
${ }^{16}$ Drezner, J. A. "Competition and Innovation Under Complexity." DTIC Document, 2009.

${ }^{17}$ Forbath, T.-d. "Learning the fine art of global collaboration," Harvard business review Vol. 86, No. 1, 2008, pp. 24-+.

${ }^{18}$ Weick, K. E. Sensemaking in organizations: Sage Publications, Inc, 1995.

${ }^{19}$ Blatt, R., Christianson, M. K., Sutcliffe, K. M., and Rosenthal, M. M. "A sensemaking lens on reliability," Journal of Organizational Behavior Vol. 27, No. 7, 2006, pp. 897-917. doi: 10.1002/job.392

${ }^{20}$ Weick, K. E., Sutcliffe, K. M., and Obstfeld, D. "Organizing and the process of sensemaking," Organization Science Vol. 16, No. 4, 2005, pp. 409-421.

doi: 10.1287 /orsc. 1050.0133

${ }^{21}$ Weick, K. E. "THE COLLAPSE OF SENSEMAKING IN ORGANIZATIONS - THE MANN GULCH DISASTER," Administrative Science Quarterly Vol. 38, No. 4, 1993, pp. 628-652. doi: $10.2307 / 2393339$

${ }^{22}$ Pye, A. "Leadership and Organizing: Sensemaking in Action," Leadership Vol. 1, No. 1, 2005, pp. 31-49. doi: $10.1177 / 1742715005049349$

${ }^{23}$ Daft, R. L., and Lengel, R. H. "ORGANIZATIONAL INFORMATION REQUIREMENTS, MEDIA RICHNESS AND STRUCTURAL DESIGN," Management Science Vol. 32, No. 5, 1986, pp. 554-571. doi: $10.1287 / \mathrm{mnsc} .32 .5 .554$

${ }^{24}$ Maitlis, S., and Sonenshein, S. "Sensemaking in Crisis and Change: Inspiration and Insights From Weick (1988)," Journal of Management Studies Vol. 47, No. 3, 2010, pp. 551-580. doi: $10.1111 / \mathrm{j} .1467-6486.2010 .00908 . \mathrm{x}$

${ }^{25}$ Weick, K. E., and Roberts, K. H. "COLLECTIVE MIND IN ORGANIZATIONS - HEEDFUL INTERRELATING ON FLIGHT DECKS," Administrative Science Quarterly Vol. 38, No. 3, 1993, pp. 357-381. doi: $10.2307 / 2393372$

${ }^{26}$ Schulman, P. R. "General attributes of safe organisations," Quality and Safety in Health Care Vol. 13, No. suppl 2, 2004, pp. ii39-ii44.

${ }^{27}$ Roe, E., and Schulman, P. R. High reliability management: Operating on the edge: Stanford University Press, 2008.

${ }^{28}$ Starbuck, W. H., and Nystrom, P. C. "WHY THE WORLD NEEDS ORGANIZATIONAL DESIGN," Journal of General Management Vol. 6, No. 3, 1981, pp. 3-17.

${ }^{29}$ Weick, K. E., Sutcliffe, K. M., and Obstfeld, D. "Organizing for high reliability: Processes of collective mindfulness," Crisis Management Vol. 3, 2008, pp. 81-123.

${ }^{30}$ Sutcliffe, K. M. "High Reliability Organizing: HROs and Health Care." University of MIchigan, 2011.

${ }^{31}$ Roberts, K. H. "Some Characteristics of One Type of High Reliability Organization," Organization Science Vol. 1, No. 2, 1990, pp. 160-176.

doi: $10.1287 /$ orsc. 1.2 .160

${ }^{32}$ LaPorte, T. R., and Consolini, P. M. "Working in practice but not in theory: theoretical challenges of" high-reliability organizations"," Journal of Public Administration Research and Theory: J-PART Vol. 1, No. 1, 1991, pp. 19-48.

${ }^{33}$ Boeije, H. "A purposeful approach to the constant comparative method in the analysis of qualitative interviews," Quality \& Quantity Vol. 36, No. 4, 2002, pp. 391-409. doi: 10.1023/a:1020909529486

${ }^{34}$ Leydens, J. A., Moskal, B. M., and Pavelich, M. J. "Qualitative methods used in the assessment of engineering education," JOURNAL OF ENGINEERING EDUCATION-WASHINGTON- Vol. 93, No. 1, 2004, pp. 65-72.

${ }^{35}$ Lofland, J., and Lofland, L. H. Analyzing social settings: a guide to qualitative observation and analysis. Belmont, Calif.: Wadsworth, 1995.

${ }^{36}$ Dye, J. S., Irene; Rosenberg, Brian; Coleman, Susanne. "Constant Comparison Method: A Kaleidoscope of Data," The Qualitative Report. Vol. Vol 4, Numbers 1/2, http://www.nova.edu/ssss/QR/index.html, 2000.

${ }^{37}$ Maxwell, J. A. "Designing a qualitative study," Handbook of applied social research methods, 1998, pp. 69-100.

${ }^{38}$ Ryan, G. B., H. Russel. "Techniques to Identify Themes," Field Methods Vol. 15, No. No. 1, 2003, pp. 85-109. doi: $10.1177 / 1525822 X 02239569$

${ }^{39}$ Pratt, M. G. "FOR THE LACK OF A BOILERPLATE: TIPS ON WRITING UP (AND REVIEWING) QUALITATIVE RESEARCH," Academy of Management Journal Vol. 52, No. 5, 2009, pp. 856-862.

${ }^{40}$ Corbin Dwyer, S., and Buckle, J. L. "The space between: On being an insider-outsider in qualitative research," International Journal of Qualitative Methods Vol. 8, No. 1, 2009, pp. 54-63. 
${ }^{41}$ Merton, R. K. "INSIDERS AND OUTSIDERS - CHAPTER IN SOCIOLOGY OF KNOWLEDGE," American Journal of Sociology Vol. 78, No. 1, 1972, pp. 9-\&. doi: 10.1086/225294

${ }^{42}$ Carlile, P. R. "Transferring, translating, and transforming: An integrative framework for managing knowledge across boundaries," Organization Science, 2004, pp. 555-568.

${ }^{43}$ Østerlund, C., and Carlile, P. "Relations in practice: Sorting through practice theories on knowledge sharing in complex organizations," The Information Society Vol. 21, No. 2, 2005, pp. 91-107.

${ }^{44}$ Akao, Y. Quality function deployment: integrating customer requirements into product design: Productivity Pr, 2004.

${ }^{45}$ Barton, D. L. "Wellsprings of knowledge," Harvard Business school Press, Boston, 1995.

${ }^{46}$ Ancona, D. "Distributed Leadership: Practices, Structures, and Culture," ICOS Lecture Series. University of Michigan, Ann Arbor, MI, 2011.

${ }^{47}$ Cameron, K. S., and Quinn, R. E. Diagnosing and changing organizational culture: Based on the competing values framework: Jossey-Bass, 2011.

${ }^{48}$ Gladwell, M. The tipping point: How little things can make a big difference: Little, Brown and Company, 2000.

${ }^{49}$ Baker, W., Cross, R., and Wooten, M. "Positive organizational network analysis and energizing relationships," Positive organizational scholarship: Foundations of a new discipline, 2003, pp. 328-342.

${ }^{50}$ Baker, W. E. Networking smart: how to build relationships for personal and organizational success: iUniverse, Incorporated, 2000.

${ }^{51}$ McMasters, J. H. "Thoughts on the Engineer of 2020, "The Future of Engineering, Science and Mathematics: Who Will Lead?"," Conference on the 50th Anniversary of Harvey Mudd College. Claremont, CA, 2006.

${ }^{52}$ McMasters, J. H. "Influencing Engineering Education: One (Acrospace) Industry Perspective," International Journal of Engineering Education Vol. 20, No. 3, 2004, pp. 353-371. 